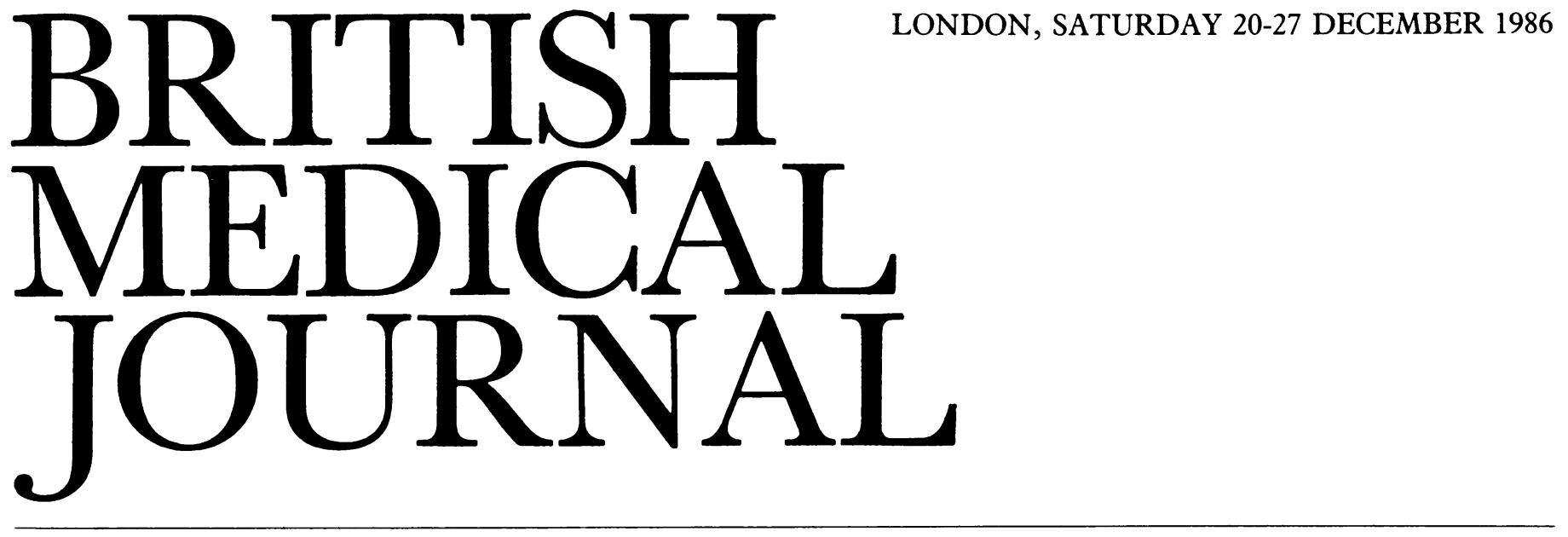

\title{
History says no to the policeman's response to AIDS
}

With both a vaccine and a cure still many years away, our immediate task in combating the acquired immune deficiency syndrome (AIDS) is to get the preventive strategy right to minimise its further spread. The crucial weapon must be education. Certainly, one may criticise the government's response as "too little, too late." Yet its new publicity campaign targeted at every household suggests that at last Westminster has awoken to the true nature of the crisis. It remains to be seen whether the British passion for working itself up into a moral lather (should we "condone vice" by issuing free condoms and needles?) will in the coming months hamper preventive work.

Education will at best, however, retard the spread of AIDS. Might then legally enforceable, coercive public health measures be esssential to protect the uninfected and future generations and to prevent AIDS reaching pandemic proportions? In New South Wales it is already a criminal offence knowingly to infect someone with the human immunodeficiency virus (HIV). Various Canadian provinces have made AIDS a notifiable disease, and had Proposition 64 been approved in California drastic powers would have been available to police the lives of sufferers.

Should we seek to curb AIDS by legal sanctions through public health agencies using notification, isolation, and prosecutions? From the days of leprosy and bubonic plague onwards governments have fought epidemics with legislation as well as information, and complex enforcement machinery has been on the statute book for well over a century. What guidance does past experience offer for present dilemmas?

Undoubtedly coercive powers have proved effective in the long run in freeing us from infectious disease. Quarantine measures taken across Europe helped halt bubonic plague from the seventeenth century. ${ }^{1}$ The same applies to the cholera pandemics of the nineteenth century. ${ }^{2}$ Emergency laws - the compulsory isolation of victims, the enforcement of standards for water supply and sewage, the regulation of burials, and so forth-provoked widespread outrage as erosions of individual liberty. But they played a part in ensuring that cholera never again swept the nation after the 1860s.

By the close of the nineteenth century coherent legislation - above all, the Public Health Act of 1875 and the Notifiable Diseases Act of 1889-empowered health authorities to act decisively-for example, by compulsory admission to hospital for specified infectious diseases. ${ }^{3}$ Thanks in part to these, typhoid, diphtheria, and other infectious diseases ceased to be scourges. This legislation is still on the statute book. One option clearly open to us is to add AIDS to the schedule of notifiable diseases. Should we?

Historical precedent says "no." For, unlike casually contagious diseases, sexually transmitted diseases constitute a special case in which the direct methods of the law have been tried, found wanting, and abandoned. The crucial experiment was the euphemistically named Contagious Diseases Acts passed in mid-Victorian times in hopes of preventing the British armed forces being defeated by syphilis. The Acts specified that in named ports and garrison towns the police should be empowered to detain any woman suspected of being a prostitute, compel her to undergo medical examination, and, if she was found to be infected, enforce treatment.

What is important is the wrath the Acts aroused. Feminists, furious at this naked application of the double standard, denounced the inevitable scapegoating (any woman seen in the company of a soldier or sailor would automatically bear a stigma). And when extending the Acts to the entire nation was mooted such leading doctors as Sir John Simon had the gravest reservations. It would encourage only secrecy and quackery and would reduce doctors to police agents, creating a perversion of medicine sure to threaten professional integrity. In any case, argued Simon and others, experience proved that the Acts simply did not work. Pressure from all sides brought their repeal. ${ }^{4}$

Since then public policy for combatting sexually transmitted disease has been voluntaristic. The fundamental principle was established by the Royal Commission of 1913, which argued that with venereal diseases, which are both hidden and shameful, securing the willing cooperation of the groups at risk would in practice achieve more than any amount of sanctions. As a consequence, anonymity and voluntariness have characterised our system of venereal disease clinics set up after the first world war. These have won the confidence of users; they have not put doctors in a false position; and they have contained the problem.

Desperate diseases may require desperate remedies. Faced with the enormity of the suffering AIDS will inflict, humanity 
demands that we at least consider draconian meaures such as compulsory screening for suspected virus carriers and further steps to protect others.

Experience suggests, however, that this would be unwise. It is a misfortune, not a crime, to contract a disease. If we begin to treat victims like criminals we alienate those whose cooperation is most needed and encourage them to behave like criminals; not least we risk turning doctors into gaolers. In any case, the law is an unsuitable instrument for fighting AIDS. To use the courts punitively-by making it a criminal offence knowingly to pass on the virus-would prove a medical nonsense and impossible to enforce. And effectively to use legal powers preventively cannot but entail scapegoating on a scale that would require a police state. For the only means whereby the law can reliably prevent carriers from spreading the virus is lifelong isolation in modern leper colonies.

Fortunately, this is quite unnecessary because effective means are already to hand to halt the spread of AIDS-not the law but the prudent behaviour of every one of us. In contrast to smallpox it takes two consenting partners to spread AIDS. The days of sex without responsibility are over. Responsible sex infringes no person's liberty. It is our only practical option.

Medical Historian,

Wellcome Institute for the History of Medicine,

London NW1 2BP

1 Slack P. The impact of plague in Tudor and Stuart England. London: Routledge and Kegan Paul, 1985

2 Pelling M. Cholera, fever, and English medicine 1825-1865. Oxford: Oxford University Press, 1978. 3 Newsholme A. Hygiene: A manual of personal and public health. London: Geo Gill and Sons, 1902. $4 \mathrm{McHugh}$ P. Prostitution and Victorian social reform. London: Croom Helm, 1980.

\section{Doctors' double standards on alcohol}

The recently published reports on alcohol from the Royal College of Psychiatrists ${ }^{1}$ and the Royal College of General Practitioners ${ }^{2}$ together with the soon to be published report from the Royal College of Physicians suggest that doctors intend to take alcohol and its abuse seriously. Until recently only a few doctors played key parts in identifying, treating, and preventing the many physical, psychological, and social problems related to alcohol abuse. Various explanations for this "addiction business" 3 have been proffered: the tendency for medical educators to regard alcohol abuse as being of little importance ${ }^{4}$; confusion concerning the concepts of dependence and disease ${ }^{5}$; a reluctance to regard alcohol abuse as a legitimate medical problem ${ }^{6}$; and authoritarian and moralistic attitudes towards heavy and dependent drinkers. ${ }^{7}$ At the same time doctors and medical students are widely thought to be heavy drinkers themselves,${ }^{89}$ and it has even been suggested that the doctor who drinks heavily "may set his own drinking habit as the norm and thus regard drinking equal to or less than his as clinically insignificant." 10

The evidence that doctors do drink to excess is persuasive. First admission rates for alcoholism in doctors in Scotland are over twice those for comparable groups, while the mortality from alcohol related cirrhosis in doctors in England and Wales is 3.5 times that in the general population. ${ }^{11}$ In 1982 more than a quarter of the disciplinary cases brought before the General Medical Council preliminary proceedings committee featured alcohol abuse. ${ }^{12}$ There may be 2000-3000 alcoholic doctors in England and Wales, ${ }^{13}$ and Caviston and Paton observed that the general increase in alcohol consumption since 1978 suggests that "the figure must be a good deal higher, and there must be many doctors whose lives and work are significantly impaired by the use of alcohol." 14 Estimates of the proportion of alcoholics among doctors range from $3 \%$ to $15 \%,{ }^{15}{ }^{16}$ although others have argued that the alcoholism rate among doctors is about the same as that among comparable groups who are not doctors. ${ }^{9}$ In one study comparing doctors and medical students with law and business studies students only $1 \%$ of the doctors admitted that drug use, drinking, or mental health problems had interrupted their medical careers. ${ }^{17}$ Most described themselves as light or infrequent drinkers, and only 3\% admitted to drinking every day. Yet almost half of the doctors in training admitted to having had a hangover at least once in the preceding year, and $15 \%$ worried that they might be drinking to excess.

A serious shortcoming with such studies is that invariably many doctors do not respond and yet that group probably contains a disproportionate number of heavy and at risk drinkers. Over one third of the Boston group drawn for study did not reply, a figure similar to that recorded by Anderson in his study of the drinking patterns of general practitioners in the Oxford region. ${ }^{18}$ Nevertheless, of those general practitioners who did reply, $12 \%$ of the men and $45 \%$ of the women were drinking amounts that were categorised as hazardous or putting them at risk.

Do medical schools cultivate alcohol abuse? Is the tolerant attitude towards drunken students itself a factor in the subsequent appearance before the General Medical Council of the dismal cohort of alcohol damaged doctors? One researcher, commenting on a follow up of 41 alcoholic doctors, 17 of whom had started their heavy drinking before their 30th birthday, observed: "As any reader of Richard Gordon knows, an ability to hold one's liquor is supposed to be almost mandatory for medical students." 11 The stress of medical student life is often blamed rather than the students' culture and attitudes to drink, and medical students and junior hospital doctors do seem to be a particularly stressed group. The stresses include interference with family life, the need to escape tension, the fear of making mistakes, and having too great a workload-all of which predispose to alcohol and drug abuse. ${ }^{1920}$ Yet, although the list of industries and local authorities developing alcohol policies is growing daily, there is little evidence of a comparable concern from doctors.

Alcohol is still readily available within medical schools, its role within medical life is engrained, and an astonishing degree of tolerance of drunkenness among medical students persists. Indeed, the recent portrayal on television of selection and initiation into medical school life did little to correct the prevailing image of the male medical student as a beer swilling philistine in search of intoxication. Doctors do not seem to recognise the need for clear guidelines concerning drinking during working or duty hours. Bars figure prominently in medical school prospectuses, while the Royal College of Physicians, in common with many medical organisations, unthinkingly and routinely provides alcohol for lunchtime conferences and educational meetings.

Is it not somewhat ironic that the same profession through 